\title{
Physical health monitoring in dementia and associations with ethnicity: a descriptive study using electronic health records
}

\section{Cini Bhanu ${ }^{1 *}$, Mary Elizabeth Jones ${ }^{1}$, Kate Walters ${ }^{1}$, Irene Petersen ${ }^{1}$, Jill Manthorpe ${ }^{2}$, Rosalind Raine ${ }^{3}$, Naaheed Mukadam ${ }^{4}$, Claudia Cooper ${ }^{4}$ \\ 'Department of Primary Care and Population Health, University College London Research, London, UK; ${ }^{2}$ NIHR Health and Social Care Workforce Research Unit, King's College London, London, UK; ${ }^{3}$ Epidemiology and Public Health, University College London, London, UK; ${ }^{4}$ Division of Psychiatry, University College London, London, UK}

*For correspondence: c.bhanu@ ucl.ac.uk

Competing interest: The authors declare that no competing interests exist.

Received: 18 December 2019 Accepted: 06 January 2020 Published: 23 September 2020

@This article is Open Access: CC BY license (https://creativecommons.org/licenses/by/4.0/)

Author Keywords: dementia, large database research, inequalities, ethnic groups, primary health care

Copyright (C) 2020, The Authors; DOI:10.3399/

bjgpopen20X101080

\begin{abstract}
Background: Good physical health monitoring can increase quality of life for people with dementia, but the monitoring may vary and ethnic inequalities may exist.
\end{abstract}

Aim: To investigate UK primary care routine physical health monitoring for people with dementia by: (a) ethnic groups, and (b) comorbidity status.

Design \& setting: A retrospective cohort study was undertaken using electronic primary care records in the UK.

Method: Physical health monitoring was compared in people with dementia from white, black, and Asian ethnic groups and compared those with $\geq 1$ comorbidity versus no comorbidity, from 1 April 2015 to 31 March 2016. Using the Dementia: Good Care Planning framework and expert consensus, good care was defined as receiving, within 1 year: a dementia review; a blood pressure (BP) check (at least one); a GP consultation (at least one); a weight and/or body mass index (BMI) recording (at least one); and an influenza vaccination.

Results: Of 20821 people with dementia, 68\% received a dementia review, $80 \%$ at least one BP recording, $97 \%$ at least one GP contact, $48 \%$ a weight and/or BMI recording, and $81 \%$ an influenza vaccination in 1 year. Compared with white people, black people were $23 \%$ less likely and Asian people $16 \%$ less likely to have weight recorded (adjusted incidence rate ratio [IRR] $=0.77,95 \%$ confidence interval $[\mathrm{Cl}]=0.60$ to $0.98 / 0.84,0.71$ to 1.00 ). People without comorbidities were less likely to have weight recorded (adjusted IRR $=0.74,95 \% \mathrm{Cl}=0.69$ to 0.79 ) and $\mathrm{BP}$ monitored (adjusted IRR $=0.71$, $95 \% \mathrm{Cl}=0.68$ to 0.75 )

Conclusion: Ethnic group was not associated with differences in physical health monitoring, other than weight monitoring. Comorbidity status was associated with weight and BP monitoring. Physical health monitoring in dementia, in particular nutrition, requires improvement.

\section{How this fits in}

Good physical health supports quality of life for people living with dementia. Routine physical health monitoring in general practice can support this and should be accessible to all. This is the first study to explore routine GP physical health monitoring and ethnic group in people living with dementia. Findings can inform policies, promoting access to good post-diagnostic support. 


\section{Introduction}

Around 850000 people live with dementia in the UK. ${ }^{1}$ By 2040, this number is likely to increase by $57 \% .^{2}$ People with dementia have high rates of physical morbidities (commonly hypertension and diabetes) that are primarily managed in general practice. ${ }^{3}$ Reducing physical morbidity improves quality of life for people with dementia ${ }^{4}$ and may slow cognitive decline..$^{5,6}$

The Dementia: Good Care Planning framework recommended an annual GP review as a minimum standard of care, as a Quality Outcomes Framework (QOF) measure in 2015. ${ }^{7}$ Routine physical health monitoring should include tailored management and prevention of comorbidities, with medication, nutrition, and hydration reviews. ${ }^{7}$

UK policies prioritise fair access to health care, ${ }^{8}$ but inequalities exist. In the UK, people from black ethnic groups living with dementia are less likely to be diagnosed, and people from Asian backgrounds less likely to receive symptomatic treatments post-diagnosis, compared with people from white ethnic groups. ${ }^{9,10}$ Rates of physical morbidities are higher among people from black and Asian backgrounds compared with the white population, ${ }^{9,11}$ so it would be concerning if health inequalities extend to preventive care for physical disorders.

The study aimed to examine routine physical health monitoring for people with dementia in UK primary care and investigate whether this differs between white, black, and Asian ethnic groups as the main objective. As a secondary objective, the study investigated physical health monitoring for the overall population by comorbidity status. Informed by guidelines ${ }^{7}$ and expert consensus, routine physical health monitoring was defined for the study (see Outcome and patient characteristics for the definition).

\section{Method}

This cohort study used electronic primary care records from UK GP practices contributing to The Health Improvement Network (THIN) database, ${ }^{12}$ which is broadly representative of the UK population. At the time of data collection, THIN included 744 general practices and 15.6 million patients in 2016 . In the UK, most physical health monitoring of people with dementia happens in primary care. ${ }^{13}$ Clinical data are coded using Read codes. ${ }^{14}$ THIN captures demographic information on: sex, ethnic group, birth year, and patient-level Townsend score (an area-based measure of social deprivation). ${ }^{15,16}$

\section{Study population}

Individuals included were aged 50-105 years contributing to THIN between 1 April 2015 and 31 March 2016 to coincide with the QOF recording year. Individuals with dementia were defined by a Read code indicating a dementia diagnosis or an anti-dementia drug prescription (cholinesterase inhibitors or memantine), as in previous studies., 90 Individuals who were registered with a GP practice in the relevant period and had received a dementia diagnosis or been prescribed anti-dementia medication prior to that date (that is, had a dementia diagnosis for the whole study period) were included. All GP practices met standard criteria for acceptable mortality reporting and computer usage. ${ }^{17,18}$

\section{Outcome and patient characteristics}

Good routine physical health care was defined as, over 1 year, a record of the following being received: a dementia review (at least one recorded); a BP measurement (at least one recorded); a GP consultation (at least one, in person or via telephone); weight and/or BMI recorded (at least one); and an influenza vaccination.

Ethnic groups were catergorised based on Office for National Statistics classification: ${ }^{9}$ white (British or other white background); Asian (Indian, Pakistani, Bangladeshi, or other Asian background); black (African, Caribbean, or other black background); and mixed or other ethnic groups (mixed, Chinese, or Arab). ${ }^{9}$ Individuals from mixed or other ethnic groups were excluded from analyses owing to small numbers $(<0.10 \%$ cohort). For comorbidity status, people were identified with a diagnosis of hypertension, myocardial infarction (MI), stroke, diabetes, or chronic kidney disease (CKD). Covariates were age, sex, Townsend score, comorbidities, and prescribing index (a valid additional measure of comorbidity ${ }^{19}$ ). Age was grouped in 10-year categories; the last category was 90-105 years owing to few individuals being aged $>100$ years. 


\section{Analyses}

Multivariable Poisson regression was used to investigate the relationship between ethnic group and the outcomes. Models were adjusted for age, sex, Townsend deprivation, comorbidities, and prescribing index. IRRs were calculated for outcomes comparing black and Asian ethnic groups with the white ethnic group. Comorbidities were also stratified comparing the cohort with and without comorbidity.

Characteristics of individuals were compared with and without the ethnic group recorded, and complete case analyses were conducted for those with a record of ethnic group and Townsend score. Missing ethnic group data were then imputed using multiple imputation by chained equations. ${ }^{20}$ Compared with complete case analysis, multiple imputation can greatly strengthen results by collating all the information available from individuals with observed data. ${ }^{21}$ This way, information was used from the full dataset in the analysis to provide more precise estimates of the outcomes (see Supplementary Box 1). The multiple imputation results presented in this article are considered to be the primary results. They were consistent with the complete case analysis. Stata (version 15.1) was used.

\section{Results}

\section{Included individuals}

Of the 20821 individuals aged 50-105 years in the study, 10570 (50.8\%) had their ethnic group recorded. Of 10570 individuals with a recorded ethnic group, 96.6\% (10 215) were recorded as from a white ethnic group, $2.1 \%$ (221) from an Asian ethnic group and 1.3\% (134) from a black ethnic group. After multiple imputation of ethnic group, $96.6 \%$ were from a white ethnic group, $2.1 \%$ from an Asian ethnic group and $1.2 \%$ from a black ethnic group (Table 1).

The mean age was 79.8 years. Among this cohort, 59\% had diabetes, 55\% had hypertension, $44 \%$ had CKD, 23\% had a stroke diagnosis, $9 \%$ had an Ml diagnosis, and 13\% had no comorbidity recorded.

There were some slight differences in age and sex distribution between those with and without ethnic group recorded (Supplementary Table 2).

\section{Annual dementia review}

An annual dementia review was recorded for 14105 (68\%) individuals with dementia. There was no significant difference in the proportion of people with dementia from black, Asian, or white ethnic groups receiving a review (Table 2). Neither was there significant difference in the proportion of people with dementia receiving a review according to comorbidity status (Table 3).

\section{Annual blood pressure monitoring}

At least one BP check was recorded in 16611 (80\%) individuals with dementia, with an average of 2.9 BP recordings per person per year. There was no significant difference in the proportion of people with dementia from black, Asian, or white ethnic groups receiving at least one BP check. Those without comorbidities were less likely to have at least one BP check, compared with those with at least one comorbidity (78\% versus $82 \%$; adjusted IRR $=0.95,95 \% \mathrm{Cl}=0.92$ to 0.98 ) (Table 2).

\section{Number of GP consultations}

At least one GP surgery, telephone or home visit consultation was recorded in 20231 (97\%) individuals with dementia. There was no significant difference in the proportion of people with dementia from black, Asian, or white ethnic groups receiving at least one GP consultation. There was also no significant difference in the proportion of people with dementia according to comorbidity status receiving at least one GP consultation (Table 2).

\section{Annual weight and/or BMI recording}

A weight and/or BMI was recorded in 9927 (48\%) individuals with dementia. Compared with white groups, black people were $23 \%$ less likely (adjusted IRR $=0.77,95 \% \mathrm{Cl}=0.60$ to 0.98 ) and Asian people $16 \%$ less likely (adjusted IRR $=0.84,95 \% \mathrm{Cl}=0.71$ to 1.00 ) to have their weight recorded. People with dementia without any comorbidities were less likely to have at least one weight and/ 
Table 1 Participant characteristics of cohort of individuals with dementia, total and by each ethnic group. As ethnic group, Townsend score of social deprivation and comorbidities were imputed and sample sizes should not be reported for imputed data, only percentages are reported for characteristics of each ethnic group and for Townsend score

\begin{tabular}{|c|c|c|c|c|}
\hline Characteristic & Number (\%) & $\%$ & $\%$ & $\%$ \\
\hline Ethnic group & All & White & Asian & Black \\
\hline Individuals & 20821 & $96.6 \%$ & $2.1 \%$ & $1.2 \%$ \\
\hline \multicolumn{5}{|l|}{ Sex } \\
\hline Male & 7457 (35.8\%) & $35.6 \%$ & $42.5 \%$ & $38.9 \%$ \\
\hline \multicolumn{5}{|l|}{ Age (years) } \\
\hline Mean $(95 \% \mathrm{Cl}$; SD) & $\begin{array}{l}79.79(79.67 \text { to } \\
79.91 ; 9.03)\end{array}$ & $\begin{array}{c}79.9(79.78 \text { to } \\
80.03 ; 9.36)\end{array}$ & $\begin{array}{c}77.27(76.23 \text { to } \\
78.31 ; 8.94)\end{array}$ & $\begin{array}{l}75.30(73.79 \text { to } \\
76.80 ; 10.63)\end{array}$ \\
\hline \multicolumn{5}{|l|}{ Age category, years } \\
\hline $50-59$ & $734(3.5 \%)$ & $3.4 \%$ & $4.6 \%$ & $10.3 \%$ \\
\hline $60-69$ & $2231(10.7 \%)$ & $10.6 \%$ & $14.5 \%$ & $15.9 \%$ \\
\hline $70-79$ & $6602(31.7 \%)$ & $31.4 \%$ & $42.4 \%$ & $39.7 \%$ \\
\hline $80-89$ & 9091 (43.7\%) & $44.1 \%$ & $33.4 \%$ & $29.4 \%$ \\
\hline$\geq 90$ & $2163(10.4 \%)$ & $10.6 \%$ & $5.1 \%$ & $4.8 \%$ \\
\hline \multicolumn{5}{|l|}{ Townsend quintile } \\
\hline 1 (least deprived) & $19.9 \%$ & $20.1 \%$ & $17.0 \%$ & $12.1 \%$ \\
\hline 2 & $24.4 \%$ & $24.7 \%$ & $22.9 \%$ & $11.5 \%$ \\
\hline 3 & $22.4 \%$ & $22.3 \%$ & $24.1 \%$ & $21.3 \%$ \\
\hline 4 & $19.5 \%$ & $19.4 \%$ & $22.1 \%$ & $24.9 \%$ \\
\hline 5 (most deprived) & $13.8 \%$ & $13.6 \%$ & $13.9 \%$ & $30.2 \%$ \\
\hline $\begin{array}{l}\text { Prescribing index }(95 \% \mathrm{Cl} \text {; } \\
\text { SD) }\end{array}$ & $\begin{array}{c}8.29 \text { (7.99 to } 8.60 ; \\
2.28)\end{array}$ & $\begin{array}{c}8.34 \text { (8.02 to } 8.66 ; \\
2.29)\end{array}$ & $\begin{array}{c}9.09 \text { (7.55 to } 10.62 ; \\
2.33)\end{array}$ & $\begin{array}{c}6.51 \text { (4.67 to } 8.35 ; \\
2.74)\end{array}$ \\
\hline \multicolumn{5}{|l|}{ Comorbidity } \\
\hline Myocardial infarction & $8.9 \%$ & $8.9 \%$ & $12.3 \%$ & $5.1 \%$ \\
\hline Stroke & $22.7 \%$ & $22.7 \%$ & $23.6 \%$ & $18.6 \%$ \\
\hline Chronic kidney disease & $43.6 \%$ & $43.4 \%$ & $49.6 \%$ & $47.4 \%$ \\
\hline Diabetes & $59.3 \%$ & $58.8 \%$ & $72.8 \%$ & $75 \%$ \\
\hline Hypertension & $55.4 \%$ & $55.3 \%$ & $61.0 \%$ & $59.3 \%$ \\
\hline No comorbidity & $12.7 \%$ & $12.8 \%$ & $7.7 \%$ & $8.8 \%$ \\
\hline
\end{tabular}

$\mathrm{Cl}=$ confidence interval. $\mathrm{SD}=$ standard deviation

or BMI check within a year, compared with people with at least one comorbidity $(36 \%$ versus $49 \%$; adjusted IRR $=0.74,95 \% \mathrm{Cl}=0.69$ to 0.79 ) (Table 2).

\section{Annual influenza vaccination}

Receipt of the annual influenza vaccination was recorded in 16781 (81\%) individuals with dementia. There was no significant difference in proportions of people with dementia from black, Asian, or white ethnic groups receiving the vaccination. There was also no significant difference in the proportion of people with dementia according to comorbidity status receiving the vaccination (Table 2). 
Table 2 Incidence rate ratio and 95\% confidence interval $(\mathrm{Cl})$ for each of the five health monitoring outcomes in the dementia cohort ( $n=20$ 821) and ethnic and comorbidity status. Results are shown for unadjusted models and model adjusted for sex, age, Townsend score, prescribing index, and comorbidities

\begin{tabular}{|c|c|c|c|c|c|c|c|c|c|c|}
\hline & \multicolumn{2}{|c|}{ Dementia QOF review } & \multicolumn{2}{|c|}{ BP monitoring } & \multicolumn{2}{|c|}{ GP consultation } & \multicolumn{2}{|c|}{ Weight/BMI } & \multicolumn{2}{|c|}{ Influenza vaccination } \\
\hline & Unadjusted & Adjusted $^{a}$ & Unadjusted & Adjusted $^{a}$ & Unadjusted & Adjusted $^{a}$ & Unadjusted & Adjusted $^{a}$ & Unadjusted & Adjusted $^{a}$ \\
\hline Total & $\begin{array}{c}14105 \\
\text { (67.7\%, 67.1\% } \\
\text { to } 68.4 \%)\end{array}$ & & $\begin{array}{c}16611 \\
(79.8 \%, 79.2 \% \\
\text { to } 80.3 \%)\end{array}$ & & $\begin{array}{c}20231 \\
(97.2 \%, 96.9 \% \\
\text { to } 97.4 \%)\end{array}$ & & $\begin{array}{c}9927 \\
(47.7 \%, 46.9 \% \\
\text { to } 48.4 \%)\end{array}$ & & $\begin{array}{c}16781 \\
(80.6 \%, 80.0 \% \\
\text { to } 81.1 \%)\end{array}$ & \\
\hline
\end{tabular}

Ethnic group

\begin{tabular}{|c|c|c|c|c|c|c|c|c|c|c|}
\hline White & 1 & 1 & 1 & 1 & 1 & 1 & 1 & 1 & 1 & 1 \\
\hline Asian & $\begin{array}{c}0.98 \\
(0.87 \text { to } 1.12)\end{array}$ & $\begin{array}{c}1.03 \\
(0.91 \text { to } 1.17)\end{array}$ & $\begin{array}{c}1.08 \\
(0.97 \text { to } 1.20)\end{array}$ & $\begin{array}{c}1.04 \\
(0.93 \text { to } 1.16)\end{array}$ & $\begin{array}{c}0.99 \\
(0.90 \text { to } 1.09)\end{array}$ & $\begin{array}{c}0.98 \\
(0.89 \text { to } 1.08)\end{array}$ & $\begin{array}{c}0.91 \\
(0.77 \text { to } 1.08)\end{array}$ & $\begin{array}{c}0.84 \\
(0.71 \text { to } 1.00)\end{array}$ & $\begin{array}{c}0.99 \\
(0.89 \text { to } 1.11)\end{array}$ & $\begin{array}{c}0.99 \\
(0.88 \text { to } 1.11)\end{array}$ \\
\hline Black & $\begin{array}{c}0.88 \\
(0.74 \text { to } 1.06)\end{array}$ & $\begin{array}{c}0.96 \\
(0.80 \text { to } 1.15)\end{array}$ & $\begin{array}{c}0.93 \\
\text { (0.80 to } 1.09)\end{array}$ & $\begin{array}{c}0.93 \\
\text { (0.80 to } 1.09)\end{array}$ & $\begin{array}{c}0.95 \\
\text { (0.83 to } 1.08)\end{array}$ & $\begin{array}{c}0.95 \\
\text { (0.84 to } 1.09)\end{array}$ & $\begin{array}{c}0.83 \\
(0.65 \text { to } 1.06)\end{array}$ & $\begin{array}{c}0.77 \\
(0.60 \text { to } 0.98)\end{array}$ & $\begin{array}{c}0.88 \\
(0.75 \text { to } 1.03)\end{array}$ & $\begin{array}{c}0.92 \\
(0.78 \text { to } 1.10)\end{array}$ \\
\hline$\geq 1$ comorbidity & 1 & 1 & 1 & 1 & 1 & 1 & 1 & 1 & 1 & 1 \\
\hline No comorbidity & $\begin{array}{c}1.05 \\
(1.00 \text { to } 1.10)\end{array}$ & $\begin{array}{c}1.06 \\
(1.00 \text { to } 1.12)\end{array}$ & $\begin{array}{c}0.69 \\
(0.65 \text { to } 0.73)\end{array}$ & $\begin{array}{c}0.71 \\
\text { (0.68 to } 0.75)\end{array}$ & $\begin{array}{c}0.97 \\
(0.93 \text { to } 1.01)\end{array}$ & $\begin{array}{c}0.98 \\
(0.94 \text { to } 1.03)\end{array}$ & $\begin{array}{c}0.72 \\
\text { (0.67 to } 0.77)\end{array}$ & $\begin{array}{c}0.74 \\
(0.69 \text { to } 0.79)\end{array}$ & $\begin{array}{c}0.92 \\
(0.88 \text { to } 0.97)\end{array}$ & $\begin{array}{c}0.95 \\
\text { (0.91 to } 1.00)\end{array}$ \\
\hline
\end{tabular}

$\mathrm{BMI}=$ body mass index. $\mathrm{BP}=$ blood pressure. $\mathrm{QOF}=$ Quality and Outcomes Famework

${ }^{a}$ A full table of covariates used in the adjusted model can be found in Supplementary Table S3.

\section{Discussion}

\section{Summary}

In this large UK primary care study, only two-thirds of people with dementia received an annual review, despite guidance recommending this as a minimum standard. ${ }^{7}$ Less than half of people with dementia in the study had a weight and/or BMI recorded; this happened less frequently in people from black and Asian ethinic groups compared with white ethnic groups, and less frequently in people without comorbidities compared with those with $\geq 1$ comorbidity. A fifth of people with dementia did not receive an influenza vaccine or a BP check within a year, and only $57 \%$ of people with dementia without other comorbidities had a BP check. Ethnic group was not associated with differences in BP monitoring, GP consultations, influenza vaccination, or dementia annual review.

\section{Strengths and limitations}

THIN comprises around $6 \%$ of the UK population, and is broadly representative in terms of demographic and health variables. ${ }^{13}$ Ethnic group was imputed to address missing data, and results from complete case and multiple imputation analyses were similar (Supplementary Table 1). Imputing missing data meant the full sample of individuals with dementia could be used to provide more precise estimates of outcomes.

Table 3 Comorbidity characteristics of cohort for each of the five health monitoring outcomes $(n=$ 20 821)

\begin{tabular}{lcccccc}
\hline & $\begin{array}{c}\text { MI } \\
(n=1864)\end{array}$ & $\begin{array}{c}\text { Stroke } \\
(n=4717)\end{array}$ & $\begin{array}{c}\text { Diabetes } \\
(n=12343)\end{array}$ & $\begin{array}{c}\text { CKD } \\
(n=9074)\end{array}$ & $\begin{array}{c}\text { Hypertension } \\
(n=11542)\end{array}$ & $\begin{array}{c}\text { No comorbidity } \\
(n=2641)\end{array}$ \\
\hline $\begin{array}{l}\text { Dementia QOF } \\
\text { review }\end{array}$ & $1214(65.1 \%)$ & $3315(70.3 \%)$ & $8176(66.2 \%)$ & $6101(67.2 \%)$ & $7870(68.2 \%)$ & $1870(70.8 \%)$ \\
\hline BP monitoring & $1660(89.1 \%)$ & $4106(87.1 \%)$ & $10419(84.4 \%)$ & $7820(86.2 \%)$ & $10101(87.5 \%)$ & $1513(57.3 \%)$ \\
\hline GP consultation & $1826(98.0 \%)$ & $4645(98.5 \%)$ & $12060(97.7 \%)$ & $8889(98 \%)$ & $11299(97.9 \%)$ & $2502(94.7 \%)$ \\
\hline Weight/BMI & $968(51.9 \%)$ & $2366(50.2 \%)$ & $6506(52.7 \%)$ & $4775(52.6 \%)$ & $5848(50.7 \%)$ & $938(35.5 \%)$ \\
\hline Influenza & $1601(85.9 \%)$ & $3991(84.6 \%)$ & $10039(81.3 \%)$ & $7560(83.3 \%)$ & $9572(82.9 \%)$ & $1985(75.2 \%)$
\end{tabular}

Vaccination

$\mathrm{CKD}=$ chronic kidney disease. $\mathrm{BMI}=$ body mass index. $\mathrm{BP}=$ blood pressure. $\mathrm{MI}=$ myocardial infarction. QOF = Quality and Outcomes Framework. 
People living with dementia were identified through a coded dementia diagnosis or anti-dementia drug repeat prescription, which may exclude a small number diagnosed with dementia within secondary care and not captured in GP records.

The study focused on ethnic group as black, Asian, or white as data at more detailed levels were not well recorded. However, this may have obscured smaller intra-group differences. Ethnic groups are considered to share a common ancestry, culture, and feeling of solidarity with one another. ${ }^{22}$ There is wide variation within minority ethnic groups in country of origin, language, religion, socioeconomic characteristics, and experiences, but enough shared culture with regards to family structures, identity, and health beliefs to make ethnic group relevant to health behaviours. ${ }^{22}$ While some comorbidities were accounted for, analyses may have been confounded by unmeasured variables (for example, overall physical health, frailty, social demographics) affecting service use. This study also had relatively low numbers of people from black and Asian backgrounds, which may have obscured smaller differences between groups.

The study investigated the likelihood of receiving at least one BP or weight and/or BMI measurement, which is a crude binary outcome and it is not known whether those with abnormal values received adequate treatment or follow-up. While Read codes were used to capture influenza vaccination delivered in other settings, some may have been missed if they were not documented in GP records.

\section{Comparison with existing literature}

To the authors' knowledge, this is the first study to explore routine GP physical health monitoring and ethnic group in people with dementia. The finding that black and Asian ethnic groups are less likely to have their weight and/or BMI recordedx adds to other known barriers to good dementia care for these groups. ${ }^{9,10}$ Contextual barriers to help-seeking among these groups include negative experiences of health services and perceptions that caring is a family responsibility. ${ }^{22-24}$ However, for most outcomes, no differences between ethnic groups were found. This may indicate that among people with dementia, barriers to accessing physical health care are shared among all ethnic groups, or that smaller differences between groups were undetected owing to small numbers of minority groups. The study found weight and/or BMI had the lowest rates of completion of all the component of monitoring studied, so perhaps inequalities emerge in less routine care activities, because clinicians are more vulnerable to unconscious bias when exercising more discretion. Lower levels of overall comorbidity were identified among white groups compared with black and Asian groups, as is consistent with the literature. ${ }^{9,11}$

The findings contrast with those investigating mental health care, where minority ethnic groups are less likely to receive anti-dementia medication where potentially indicated and receive antipsychotic medication for longer. ${ }^{10}$ The impact of stigma on mental health care access compared with physical health care may explain this difference.

Between 2002-2013, dementia annual review uptake was under $50 \% .{ }^{25}$ The results of the present study show an improvement in 2015-2016 (possibly related to QOF guidance), ${ }^{7}$ but still a third of people with dementia had no review recorded, despite most having at least one annual GP contact. This lack of review is important as pressures on secondary mental health services are rising, and responsibility for routine monitoring may increasingly fall to primary care. Guidelines for the annual dementia review are extensive; they emphasise a tailored review to consider physical health, mental health, nutrition, optimising polypharmacy, care needs, functional ability, and end-of-life discussions, among other areas. ${ }^{7}$ Such broad guidance may challenge GPs facing workload and time pressures. ${ }^{26}$ Some studies suggest that GPs may believe they have little to offer patients with dementia. ${ }^{27}$ The rationale for the dementia review needs to be clearly explained, including the importance of routine physical health monitoring to dementia outcomes. Other factors explaining low uptake may include varying QOF renumeration ${ }^{28}$ and stigma related to dementia; ${ }^{29}$ GPs may be undertaking the dementia review tasks, but not recording them as such.

While dementia detection and diagnosis rates in primary care are rising, ${ }^{30}$ the findings suggest optimal care post-diagnosis lags behind. The study found less than half of people with dementia had a weight and/or BMI recorded, consistent with another THIN study reporting $47 \%$ had this recorded in 2010-2013, ${ }^{25}$ and other reports of poor weight recording in primary care. ${ }^{31}$ Eating and drinking difficulties are common in dementia. The risk of malnutrition increases as dementia progresses and 
people with dementia have 10 times more malnutrition or dehydration-related hospital admissions compared with age-matched controls. ${ }^{32}$ Anti-dementia drugs causing side effects, such as nausea, can also exacerbate difficulties. Other research has highlighted concerns that nutrition support for older people is insufficient ${ }^{33}$ and weight loss may not be recognised as a problem. ${ }^{34}$

The study found over $80 \%$ of people with dementia had at least one BP check, one GP contact, and the influenza vaccination, confirming previous studies. ${ }^{25,35}$ An annual BP check is not specified in guidelines, although this was used as a marker of good preventive health care. While some studies suggest that good BP control can reduce risk of further cerebrovascular changes, others describe a complex relationship between optimal BP and dementia. ${ }^{36}$ People with dementia are more likely to experience postural hypotension and adverse effects of low $\mathrm{BP}_{1}{ }^{37}$ which is an argument for regular monitoring, regardless of comorbidities. However, standard BP monitoring may cause anxiety, ${ }^{38}$ so should be considered carefully.

\section{Implications for research and practice}

The results suggest routine physical health monitoring for people living with dementia, particularly nutrition monitoring, is inconsistent and requires improvement. Much emphasis in primary care has been on dementia detection, where meaningful improvements have been achieved and sustained. Priorities should now shift to post-diagnosis support. ${ }^{39}$ Dementia should be considered a long-term health condition requiring routine monitoring in its own right. At present, guidelines for the annual dementia review are extensive. Prioritising components of the review that are realistic and achievable in general practice should be central to any revisions. Improved weight recording and management of nutrition should be prioritised, promoting ethnic and sex equalities in access. The role of BP monitoring, particularly for people living with dementia without other cardiovascular risk factors, should be considered by researchers. Defining best practice in physical healthcare monitoring and management of comorbidities could shape future dementia guidelines.

\section{Funding}

This work was funded by The Dunhill Medical Trust (grant number: R530/1116).

\section{Ethical approval}

The NHS South-East Multi-Centre Research Ethics Committee approved the use of THIN for scientific research in 2003. The IQVIA World Publications Scientific Review Committee granted scientific approval in March 2017 (reference number: 17THIN019).

\section{Provenance}

Freely submitted; externally peer reviewed.

\section{References}

1. Prince $M$, Bryce $R$, Albanese $E$, et al. The global prevalence of dementia: a systematic review and metaanalysis. Alzheimers Dement 2013; 9(1): 63-75. DOI: https://doi.org/10.1016/j.jalz.2012.11.007

2. Ahmadi-Abhari S, Guzman-Castillo M, Bandosz $P$, et al. Temporal trend in dementia incidence since 2002 and projections for prevalence in England and Wales to 2040: modelling study. BMJ 2017; 358: j2856. DOI: https://doi. org/10.1136/bmj.j2856

3. Poblador-Plou B, Calderón-Larrañaga A, Marta-Moreno J, et al. Comorbidity of dementia: a cross-sectional study of primary care older patients. BMC Psychiatry 2014; 14(1): 84. DOI: https://doi.org/10.1186/1471-244X-14-84

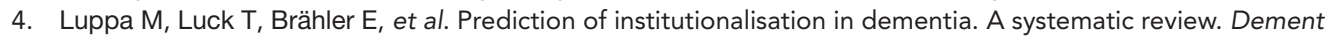
Geriatr Cogn Disord 2008; 26(1): 65-78. DOI: https://doi.org/10.1159/000144027

5. Walker KA, Power MC, Gottesman RF. Defining the relationship between hypertension, cognitive decline, and dementia: a review. Curr Hypertens Rep 2017; 19(3): 24. DOI: https://doi.org/10.1007/s11906-017-0724-3

6. Bordier L, Doucet J, Boudet J, et al. Update on cognitive decline and dementia in elderly patients with diabetes. Diabetes Metab 2014; 40(5): 331-337. DOI: https://doi.org/10.1016/j.diabet.2014.02.002

7. NHS England. Dementia: good care planning — information for primary care providers and commissioners. 2017; https://www.england.nhs.uk/publication/dementia-good-care-planning-information-for-primary-care-andcommissioners/ (accessed 17 Jun 2020)

8. Department of Health. Living well with dementia: a national dementia strategy. London: DHSC; 2009

9. Pham TM, Petersen I, Walters K, et al. Trends in dementia diagnosis rates in UK ethnic groups: analysis of UK primary care data. Clin Epidemiol 2018; 10: 949-960. DOI: https://doi.org/10.2147/CLEP.S152647 
10. Jones ME, Petersen I, Walters $\mathrm{K}$, et al. Differences in psychotropic drug prescribing between ethnic groups of people with dementia in the United Kingdom. Clin Epidemiol 2020; 12: 61-71. DOI: https://doi.org/10.2147/CLEP. S222126

11. Chaturvedi N. Ethnic differences in cardiovascular disease. Heart 2003; 89(6): 681-686. DOI: https://doi.org/10. 1136/heart.89.6.681

12. Blak BT, Thompson M, Dattani H, et al. Generalisability of the health improvement network (thin) database: demographics, chronic disease prevalence and mortality rates. Inform Prim Care 2011; 19(4): 251-255. DOI: https://doi.org/10.14236/jhi.v19i4.820

13. Goodwin N, Curry N, Naylor C, et al. Long term conditions medical management. 2012King's Fund; https://www. kingsfund.org.uk/sites/default/files/field/field_document/managing-people-long-term-conditions-gp-inquiryresearch-paper-mar11.pdf (accessed 17 Sep 2020).

14. Booth N. What are the Read codes? Health Libr Rev 1994; 11(3): 177-182. DOI: https://doi.org/10.1046/j.13652532.1994.1130177.x

15. INPS. General practice. A new modern vision for general practice. The heart of the modern NHS. 2017; https:// www.visionhealth.co.uk/vision-for-primary-care/ (accessed 17 Jun 2020).

16. Townsend P, Phillimore P, Beattie A. Health and Deprivation: Inequality and the North. London: Croom Helm; 1987.

17. Maguire A, Blak BT, Thompson M. The importance of defining periods of complete mortality reporting for research using automated data from primary care. Pharmacoepidemiol Drug Saf 2009; 18(1): 76-83. DOI: https://doi.org/10. 1002/pds. 1688

18. Horsfall $\mathrm{L}$, Walters $\mathrm{K}$, Petersen I. Identifying periods of acceptable computer usage in primary care research databases. Pharmacoepidemiol Drug Saf 2013; 22(1): 64-69. DOI: https://doi.org/10.1002/pds.3368

19. Brilleman SL, Salisbury C. Comparing measures of multimorbidity to predict outcomes in primary care: a cross sectional study. Fam Pract 2013; 30(2): 172-178. DOI: https://doi.org/10.1093/fampra/cms060

20. Sterne JAC, White IR, Carlin JB, et al. Multiple imputation for missing data in epidemiological and clinical research: potential and pitfalls. BMJ 2009; 338(1): b2393): b2393: . DOI: https://doi.org/10.1136/bmj.b2393

21. Rubin DB. Inference and missing data. Biometrika 1976; 63(3): 581-592. DOI: https://doi.org/10.1093/biomet/63.3. 581

22. Mukadam N, Cooper C, Basit B, et al. Why do ethnic elders present later to UK dementia services? A qualitative study. Int Psychogeriatr 2011; 23(7): 1070-1077. DOI: https://doi.org/10.1017/S1041610211000214

23. Berwald S, Roche M, Adelman S, et al. Black African and Caribbean British Communities' Perceptions of Memory Problems: "We Don't Do Dementia.". PLoS One 2016; 11(4): e0151878. DOI: https://doi.org/10.1371/journal. pone. 0151878

24. Nair $P, B$ hanu $C$, Frost $R$, et al. A systematic review of older adults' attitudes towards depression and its treatment. Gerontologist 2020; 60(1): e93-e104. DOI: https://doi.org/10.1093/geront/gnz048

25. Cooper $\mathrm{C}$, Lodwick R, Walters $\mathrm{K}$, et al. Inequalities in receipt of mental and physical healthcare in people with dementia in the UK. Age Ageing 2016; 46(3): 393-400.

26. Hobbs FDR, Bankhead C, Mukhtar T, et al. Clinical workload in UK primary care: a retrospective analysis of 100 million consultations in England, 2007-14. The Lancet 2016; 387(10035): 2323-2330. DOI: https://doi.org/10.1016/ S0140-6736(16)00620-6

27. Ahmad S, Orrell M, lliffe S, et al. GPs' attitudes, awareness, and practice regarding early diagnosis of dementia. $\mathrm{Br} J$ Gen Pract 2010; 60(578): e360-e365. DOI: https://doi.org/10.3399/bjgp10X515386

28. NHS Digital. Quality and Outcomes Framework - prevalence, achievements and exceptions report, England, 2015-16. 2016; http://www.content.digital.nhs.uk/catalogue/PUB22266/qof-1516-rep-v2.pdf (accessed 18 Jun 2020).

29. Swaffer K. Dementia: stigma, language, and dementia-friendly. Dementia 2014; 13(6): 709-716. DOI: https://doi. org/10.1177/1471301214548143

30. NHS Digital. Recorded dementia diagnoses. 2019; https://digital.nhs.uk/data-and-information/publications/ statistical/recorded-dementia-diagnoses (accessed 18 Jun 2020).

31. Petersen I, Welch CA, Nazareth I, et al. Health indicator recording in UK primary care electronic health records: key implications for handling missing data. Clin Epidemiol 2019; 11: 157-167. DOI: https://doi.org/10.2147/CLEP. S191437

32. Abdelhamid A, Bunn D, Copley M, et al. Effectiveness of interventions to directly support food and drink intake in people with dementia: systematic review and meta-analysis. BMC Geriatr 2016; 16(1): 26. DOI: https://doi.org/10. 1186/s12877-016-0196-3

33. Avgerinou C, Bhanu C, Walters $\mathrm{K}$, et al. Supporting nutrition in frail older people: a qualitative study exploring views of primary care and community health professionals. Br J Gen Pract 2020; 70(691): e138-e145. DOI: https:// doi.org/10.3399/bjgp20X707861

34. Avgerinou C, Bhanu C, Walters $\mathrm{K}$, et al. Exploring the views and dietary practices of older people at risk of malnutrition and their carers: a qualitative study. Nutrients 2019; 11(6): 1281. DOI: https://doi.org/10.3390/ nu11061281

35. Shah SM, Carey IM, Harris $\mathrm{T}$, et al. The impact of dementia on influenza vaccination uptake in community and care home residents. Age Ageing 2012; 41(1): 64-69. DOI: https://doi.org/10.1093/ageing/afr135

36. Walker KA, Power MC, Gottesman RF. Defining the relationship between hypertension, cognitive decline, and dementia: a review. Curr Hypertens Rep 2017; 19(3): 24. DOI: https://doi.org/10.1007/s11906-017-0724-3

37. Fernando $\mathrm{E}$, Fraser $\mathrm{M}$, Hendriksen $\mathrm{J}$, et al. Risk factors associated with falls in older adults with dementia: a systematic review. Physiother Can 2017; 69(2): 161-170. DOI: https://doi.org/10.3138/ptc.2016-14 
38. Conroy SP, Harrison JK, Van Der Wardt V, et al. Ambulatory blood pressure monitoring in older people with dementia: a systematic review of tolerability. Age Ageing 2016; 45(4): 456-462. DOI: https://doi.org/10.1093/ ageing/afw050

39. Department of Health and Social Care. Joint declaration on post-diagnostic dementia care and support. Policy Paper. 2016; https://www.gov.uk/government/publications/dementia-post-diagnostic-care-and-support/dementiapost-diagnostic-care-and-support (accessed 18 Jun 2020). 